\title{
Liver transplantation for neuropsychiatric Wilson disease
}

\author{
Narmin Kassam MD, Norbert Witt MD, Norman Kneteman MD, Vincent G Bain MD
}

N Kassam, N Witt, N Kneteman, VG Bain. Liver transplantation for neuropsychiatric Wilson disease. Can J Gastroenterol 1998;12(1):65-68. Although neuropsychiatric manifestations are prominent in some patients with Wilson disease, there is little published information regarding the efficacy of liver transplantation for these patients. A 22-year-old male with advanced neurological impairment and prominent psychiatric manifestations due to Wilson disease who underwent liver transplantation is presented. After transplantation, the ceruloplasmin and copper studies normalized and eventually the Kayser-Fleischer rings disappeared. Neurological recovery was very slow and incomplete, and his behavioural and personality disorder was entirely unaffected. He committed suicide 43 months post-transplantation. A review of the small number of related published cases in the English language literature shows variable neurological recovery post-transplantation, but the course of psychiatric manifestations is virtually never described. This case suggests that one must be cautious regarding liver transplantation for Wilson disease in patients with prior psychiatric manifestations. Aggressive medical management is likely to be preferable in most cases.

Key Words: Liver transplantation, Wilson disease

\section{Transplantation hépatique pour maladie neuropsychiatrique de Wilson}

\begin{abstract}
RÉSUMÉ : Bien que les manifestations neuropsychiatriques soient importantes chez certains patients atteints de la maladie de Wilson, quelques études ont mentionné l'efficacité de la transplantation hépatique chez ces patients. On présente ici le cas d'un homme de 22 ans souffrant d'une atteinte neurologique avancée et de manifestations psychiatriques importantes liées à la maladie de Wilson et qui a subi une transplantation hépatique. Après la transplantation, les taux de céruloplasmine et de cuivre se sont normalisés et les anneaux de Kayser-Fleischer ont éventuellement disparu. La récupération neurologique a été très lente et partielle et les troubles du comportement et de la personnalité sont restés inchangés. Il s'est suicidé 43 mois après la transplantation. Un survol des cas peu nombreux publiés en langue anglaise révèle des taux variables de récupération neurologique après la transplantation, mais on ne mentionne pour ainsi dire nulle part l'évolution des manifestations psychiatriques. Ce cas souligne la prudence qui s'impose en matière de transplantation hépatique chez des patients atteints de la maladie de Wilson et dont les manifestations psychiatriques sont déjà en place. Un traitement médical énergique risque d'être préférable dans la plupart des cas.
\end{abstract}



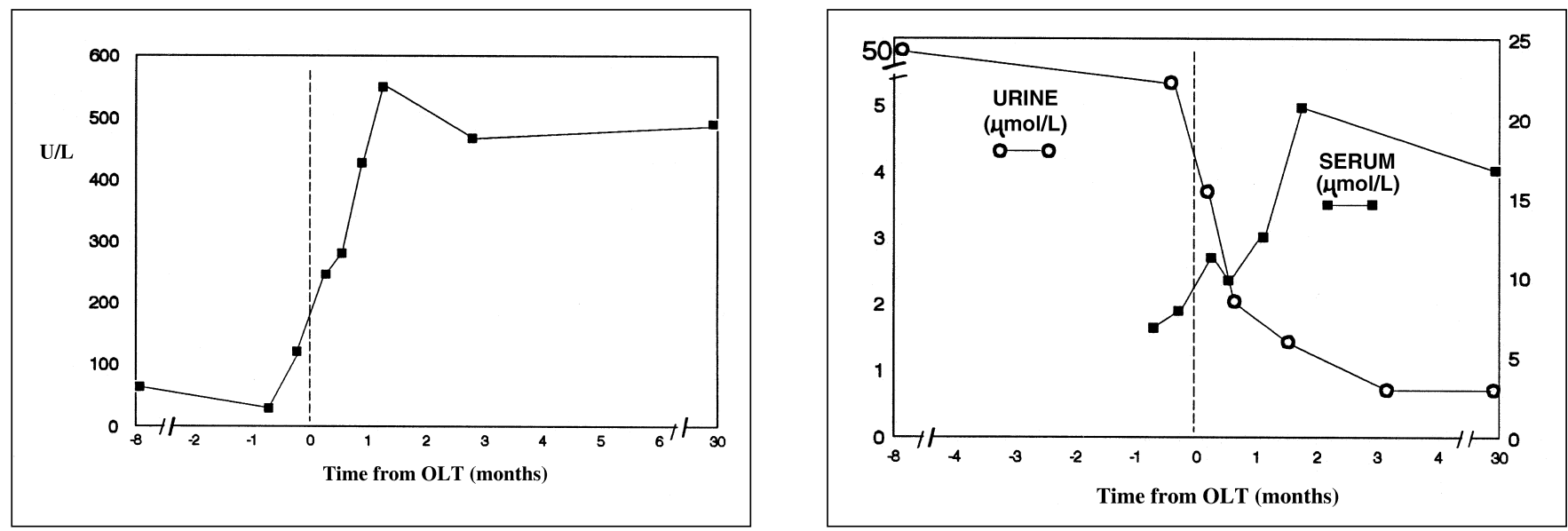

Figure 1) Sequential ceruloplasmin (left) and copper (right) studies showing normalization post-orthotopic liver transplantation (OLT). Time zero corresponds to the date of transplantation

OLT to treat hepatic failure in Wilson disease has been very successful, with demonstrable decoppering within weeks. A recent survey by Schilsky et al (4) reported 55 patients with Wilson disease who had undergone OLT in the United States and Europe, of whom eight had neurological or psychiatric manifestations. At a mean of 2.7 years (range three months to 20 years) follow-up, 43 (78\%) were still alive; of the 12 who died, four had had central nervous system (CNS) manifestations pretransplantation. The authors concluded that Wilson disease patients with overt CNS pathology had a poor outcome following OLT. However, as illustrated by the absolute numbers, experience with OLT in neurological Wilson disease is limited and therefore its role still remains unclear. Even less clear is the effect of OLT on the psychiatric manifestations of Wilson disease.

\section{CASE PRESENTATION}

A 22-year-old male was admitted to hospital on October 11, 1989 with marked neurological deterioration secondary to Wilson disease for consideration of OLT. He had first noticed symptoms - difficulty driving, ataxia and falling grades at university - in autumn 1988. The diagnosis of Wilson disease was made in early 1989 , by which time the patient displayed dysarthria, dystonia, bradykinesia and prominent Kayser-Fleischer rings. His ceruloplasmin was $73 \mathrm{U}$ (normal 210 to 570 ) and urine copper was $50 \mu \mathrm{mol} / \mathrm{L}$ (0.1 to 0.8$)$. He was promptly started on D-penicillamine at a dose of $250 \mathrm{mg}$ qid. Although his mobility improved mildly, his speech continued to deteriorate and he was moderately dystonic. Seven months later he was switched to trientene $250 \mathrm{mg}$ tid but nevertheless his gait became progressively more broad based and eventually he became immobile. He displayed significant behaviour and personality abnormalities including sexual disinhibition.

At the time of liver transplant assessment, liver function tests were aspartate aminotransferase (AST) $355 \mathrm{U} / \mathrm{L}$ (normal range 0 to 35), alkaline phosphatase (ALP) $350 \mathrm{U} / \mathrm{L}$ (30 to 120 ), bilirubin $12 \mu \mathrm{mol} / \mathrm{L}$ (2 to 18 ) and albumin $36 \mathrm{~g} / \mathrm{L}$. Ceruloplasmin level was $43 \mathrm{U}$, urine copper was $5.2 \mu \mathrm{mol} / \mathrm{L}$ and serum copper was $5.8 \mu \mathrm{mol} / \mathrm{L}$ (normal range 11 to 28 ). A liver biopsy was fragmented, and a diagnosis of cirrhosis could not be made. There was evidence of chronic hepatitis, with interface necrosis and lobular changes including focal necrosis, hepatocyte ballooning, multinucleation and nuclear glycogen inclusions. Insufficient tissue was obtained for copper quantification but was subsequently performed on the explanted liver (see below). Computed tomographic (CT) scan of the head showed extensive low density changes in the basal ganglia bilaterally and frontal atrophy, consistent with Wilson disease. These CT findings are common in most patients with Wilson disease and often are reversed with treatment (5).

The patient was accepted for OLT on the basis of progressive medically unresponsive neurological deterioration from Wilson disease despite seemingly mild hepatic disease. Transplantation was carried out on October 21, 1989 without complication. The explanted liver revealed established cirrhosis and patchy inflammatory changes. The liver's copper content was $3.3 \mu \mathrm{mol} / \mathrm{g}$ (normal 0.25 to 1.0 ). Postoperatively the patient had evidence of good early graft function and showed progressive decline in his urinary copper levels (Figure 1). Induction immunosuppression comprised Minnesota anti-lymphocyte globulin for three days, then conversion to OKT3 due to profound thrombocytopenia for an additional seven days. The patient received azathioprine and corticosteroids starting perioperatively, and cyclosporine was added on day 5 . His postoperative course was complicated by cytomegalovirus (CMV) infection, which responded well to treatment with CMV hyperimmunoglobulin.

Two weeks post-transplantation the patient remained dystonic with no spontaneous limb movement. Two months after transplantation he had mild reduction in tone and rigidity with increasing limb movement. By three months, he was able to transfer from bed to chair, and put on a shirt without assistance. By four months, he remained dystonic but was able to move all four limbs spontaneously and was able to bear weight. Throughout the postoperative course he displayed significant behavioural disturbance and was unco- 
operative with his caregivers, at times displaying aggressive and defiant behaviour, as well as emotional lability and disinhibition. These behaviours were similar to his pretransplantation state. Psychological testing revealed no intellectual impairment.

At six months post-transplantation, the patient demonstrated increasing displays of sexual disinhibition and aggression. Neurologically, he had dystonia, especially of his neck, and generalized hypertonia and bradykinesia, for which he was started on carbidopa-levadopa and bromocriptine. His mobility improved; one year after transplantation he was able to roll, sit up, transfer and stand up for brief periods. The Kayser-Fleischer rings gradually faded and completely disappeared. He was discharged from hospital to a group home, but he repeatedly alienated himself due to inappropriate behaviour and demands.

His liver function remained completely normal until 19 months post-transplantation when he developed progressively raised liver enzymes: AST $436 \mathrm{U} / \mathrm{L}$, ALP $148 \mathrm{U} / \mathrm{L}$ and bilirubin $21 \mu \mathrm{mol} / \mathrm{L}$. Liver biopsy showed parenchymal changes consistent with hepatitis, as well as mild acute rejection. Hepatitis $\mathrm{C}$ was diagnosed serologically (positive by enzyme immunoassay and recombinant immunoblot assay testing). At 26 months post-transplantation, although his neurological function was improving and he was increasingly mobile, he started to display suicidal gestures and required antipsychotic medication to control his behaviour. Three years after transplantation, he refused to take cyclosporine because of perceived association with chronic foot pain. Liver biopsy showed moderate cellular rejection and cholestasis. He was treated with pulse corticosteroids and OKT3. Upon discharge, however, he continued to take cyclosporine only sporadically, resulting in significant ongoing rejection with evolution to ductopenia on repeat biopsy and further deterioration of liver function. Despite numerous readmissions, supportive care and counselling, he committed suicide in May 1993, 43 months post-transplantation. Permission for limited autopsy only was obtained. The liver showed a portal mononuclear infiltrate, cholestasis and ductopenia typical of chronic rejection. The liver copper level was $2.06 \mu \mathrm{mol} / \mathrm{g}$.

\section{DISCUSSION}

This report describes a patient with severe neurological and psychiatric impairment secondary to Wilson disease who underwent OLT. Transplantation resulted in reversal of the metabolic defect and dramatic mobilization of copper, as demonstrated by normalization of the serum ceruloplasmin, decline of urine copper excretion (Figure 1) and disappearance of the Kayser-Fleischer rings. Clinically, he progressed from being bedridden to ambulating well enough to care for himself outside hospital. However, unlike most published cases (6-9), he did not show complete neurological recovery even up to 3.5 years after OLT. Moreover, he continued to display manipulative behaviour and emotional lability, resulting in noncompliance with medications, several acute rejection episodes and subsequently chronic ductopenic rejection.
Review of the English language literature reveals five published case reports in which OLT was performed in patients with severe neurological impairment secondary to Wilson disease. The first was a 14-year-old male who presented at age 11 years with liver disease (6). He developed moderate neurological impairment over one year with tremor and athetosis. Chelation treatment failed, and the patient developed progressive dysarthria, dystonia and choreoathetosis. OLT was performed primarily because of his crippling neurological status, although he also showed moderate hepatic impairment. In the first 12 months after OLT, he showed intermittent neurological improvement, and by 18 months he had definite improvement. A follow-up letter to the editor indicated that the patient displayed no neurological dysfunction at 50 months post-transplantation (7).

The second case involved a 13-year-old boy who presented with subacute hepatitis and developed ataxia and cogwheel rigidity (8). Despite medical treatment he went into liver failure. OLT resulted in gradual improvement of neurological function, except for a right-sided hemiparesis, which resolved by 15 months. Other psychiatric symptoms were not mentioned in either of these cases.

Two cases were reported by Polson et al (9). A 30year-old male presented with jaundice and fatigue with progressive neurological deterioration over one year. Despite treatment with D-penicillamine, he developed dysarthria, dysphagia, akinesia and rigidity, eventually becoming bedridden and unable to walk, speak or feed himself. OLT was performed 16 months after initial presentation. Over the ensuing two months, the patient showed considerable improvement and by four months he was mobile and conversing, feeding and caring for himself. He displayed mild extrapyramidal signs, as well as emotional lability and immature behaviour. The neurological symptoms completely disappeared by eight months but no further comment was made about the psychiatric symptoms.

The second patient reported by Polson et al (9) was a 27 year-old female who initially presented with abnormal liver function and pancytopenia. She developed unspecified psychological symptoms, ataxia, cogwheel rigidity and fine tremor. There was no improvement with D-penicillamine treatment, and within six months she displayed slurring dysarthria, increased muscle tone and dysdiadochokinesis. OLT was done eight years after the initial diagnosis for deteriorating neurological and liver function. Postoperatively, liver enzymes normalized but neurological function remained unchanged. By three months, she had improved, with only mild dysarthria, tremor and an unsteady gait remaining. By five months, her neurological signs had further improved, but she still displayed unspecified behavioural problems.

The fifth case, recently reported by Mason and coworkers (10), described a 20-year-old male with neuropsychiatric Wilson disease manifested by ataxia, dysarthria, dystonia and psychotic depression with mood swings. OLT was performed five years after diagnosis, when his symptoms were not improving on medical therapy. He showed inter- 
mittent improvement three weeks after transplantation in all motor functions, and regained speech at six weeks. Unfortunately he died of a ruptured splenic artery aneurysm shortly thereafter.

These cases all showed favourable, if not dramatic, improvements in neurological symptoms after OLT. Publication bias may lead to under-reporting of those with an unfavourable outcome; indeed, we did not come across any of the latter in our search. In addition, the psychiatric symptoms so prominent in our patient were not clearly documented in the published cases, and therefore the outcome after OLT of patients with symptoms similar to those of our patient is uncertain.

Despite increasing experience with liver transplantation in Wilson disease and confidence that the biochemical defect will be reversed, it is still unclear whether OLT should be considered in all patients with neuropsychiatric manifestations of Wilson disease who do not respond to chelation. If a patient has already achieved complete or near complete copper clearance, any persisting neuropsychiatric abnormalities might be considered permanent. Our patient had a poor outcome despite high postchelation hepatic copper levels $(3.3 \mu \mathrm{mol} / \mathrm{g})$. Despite 43 months of follow-up until his death, our patient showed no discernable improvement of his psychiatric disorder. Unfortunately, the only previously published example of OLT in Wilson disease primarily for neuropsychiatric indications had only six weeks of follow-up due to early death from a ruptured splenic aneurysm (10). Patients with psychiatric manifestations may be especially poor candidates for OLT because reversal of these features has never been reported and because these patients also have severe neurological impairment (1).

Would earlier liver transplantation be beneficial in patients who display a predominance of neuropsychiatric symptoms of Wilson disease? Past experience has shown that a majority of such patients respond well to medical treatment. Furthermore, it is impossible to predict which patients will not respond to medical treatment and who therefore should receive a transplant. The distinction between reversible and irreversible CNS functional changes remains difficult. It is hoped that newer imaging modalities will be useful in this regard (11). Currently, early OLT cannot be advocated with the limited data available. Indeed, early diagnosis and institution of medical treatment remain the primary goals in preventing irreversible damage to all organ systems from copper overload.

ACKNOWLEDGEMENTS: The authors thank Vie Wynnyk for her skill in manuscript preparation and computer graphics.

\section{REFERENCES}

1. Dening TR. Psychiatric aspects of Wilson's disease. Br J Psychiatry 1985;147:677-82.

2. Sternlieb I. Perspectives on Wilson's disease. Hepatology 1990;12:1234-9.

3. Sternlieb I. Wilson's disease: indications for liver transplants. Hepatology 1984;4:15S-7S.

4. Schilsky ML, Scheinberg IH, Sternlieb I. Liver transplantation for Wilson's disease: indications and outcome. Hepatology 1994;19:583-7.

5. Williams FJB, Walsne JM. Wilson's disease: an analysis of the cranial computerized tomographic appearances found in 60 patients and the changes in response to treatment with chelating agents. Brain 1981;104:735-52.

6. Groth CG, Dubois RS, Corman J, et al. Metabolic effects of hepatic replacement in Wilson's disease. Transplant Proc 1973;5:829-33.

7. Beart RW, Putnam CW, Porter KA, Starzl TE. Liver transplantation for Wilson's disease. Lancet 1975;ii:176-7. (Lett)

8. Zitelli BJ, Malatack JJ, Gartner JC Jr, Snaw BW, Iwatsuki S, Starzl TE. Orthotopic liver transplantation in children with hepatic-based metabolic disease. Transplant Proc 1983;15:1285-7.

9. Polson RJ, Rolles K, Calne RY, Williams R, Marsden D. Reversal of severe neurological manifestations of Wilson's disease following orthotopic liver transplantation. Q J Med 1987;64:685-91.

10. Mason AL, Marsh W, Alpers DH. Intractable neurologic Wilson's disease treated with orthotopic liver transplantation. Dig Dis Sci 1993;38:1746-50.

11. Starosta-Rubinstein S, Young AB, Kluin K, et al. Clinical assessment of 31 patients with Wilson's disease: Correlations with structural changes on magnetic resonance imaging. Arch Neurol $1987 ; 44: 365-70$. 


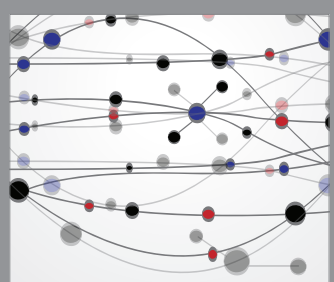

The Scientific World Journal
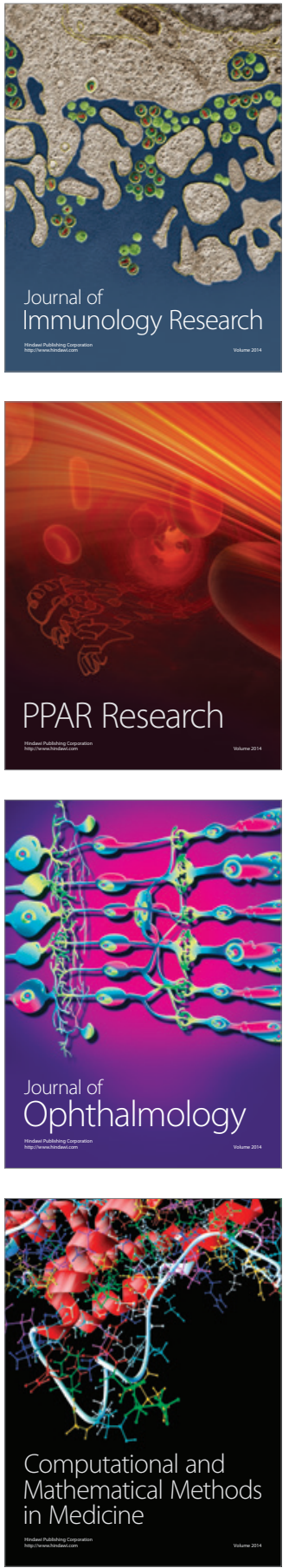

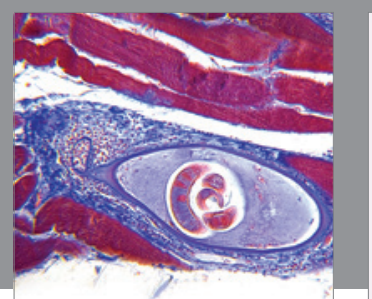

Gastroenterology Research and Practice

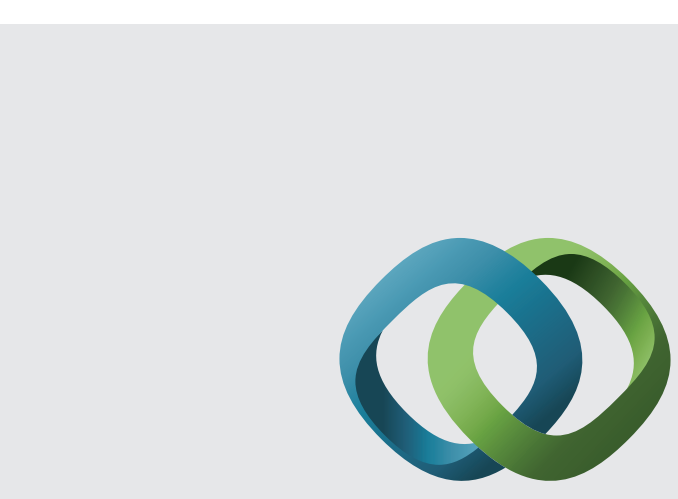

\section{Hindawi}

Submit your manuscripts at

http://www.hindawi.com
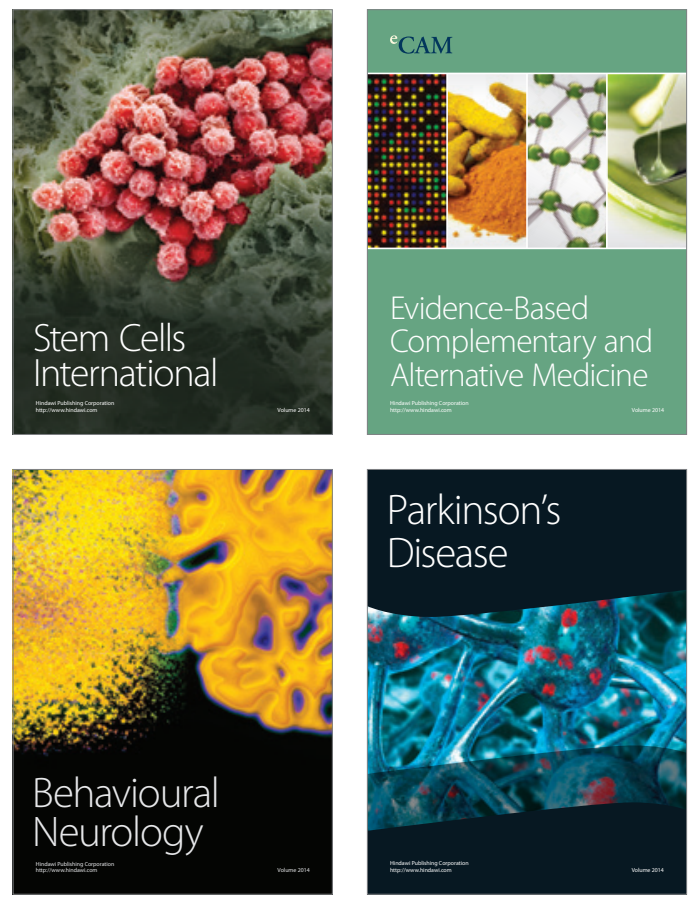
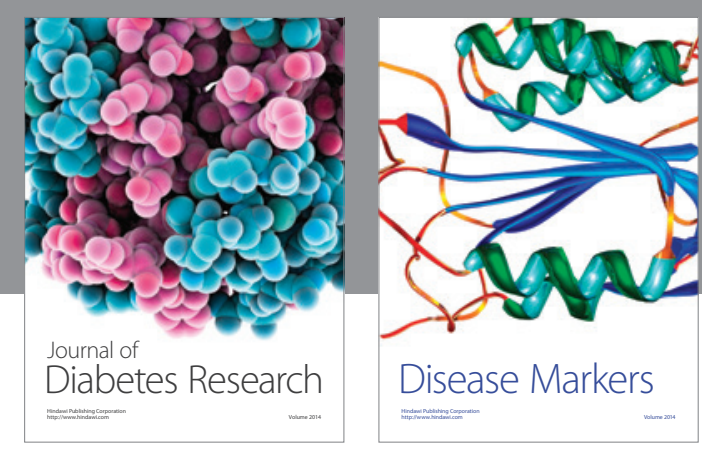

Disease Markers
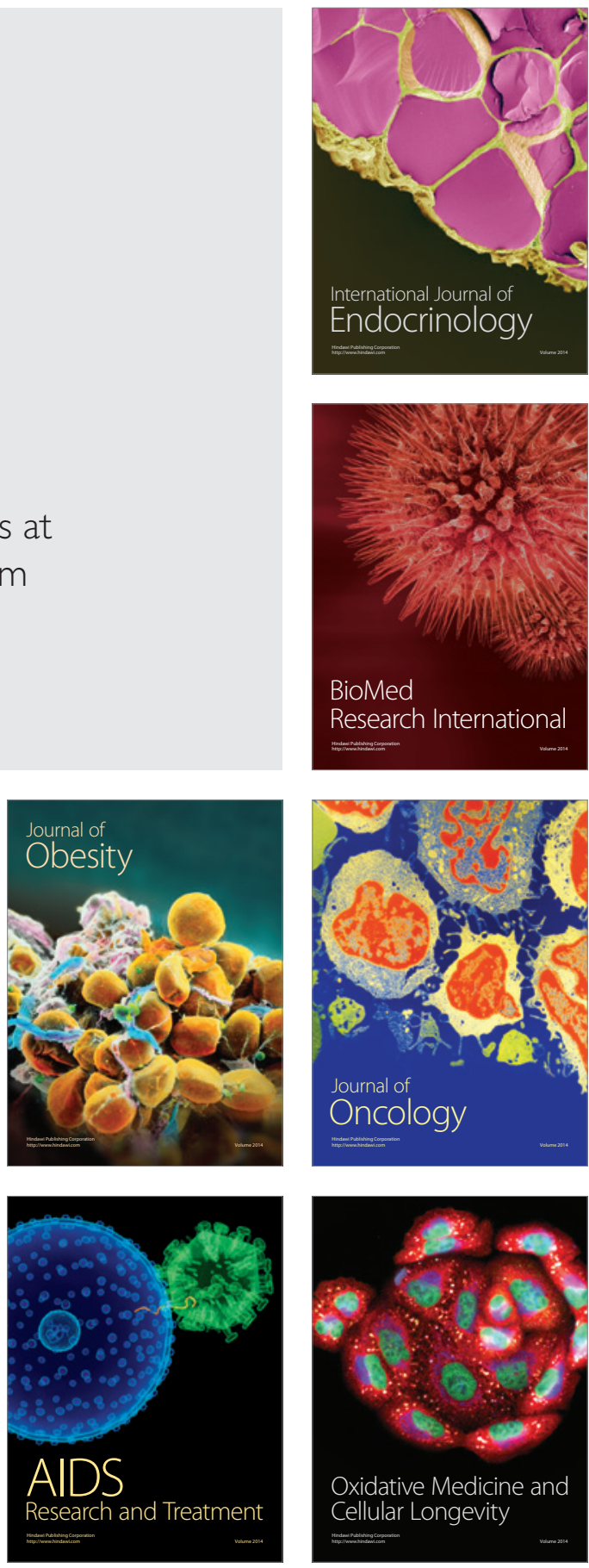